\title{
Slip Ring Device
}

National Cancer Institute

\section{Source}

National Cancer Institute. Slip Ring Device. NCI Thesaurus. Code C50149.

A ring-shaped electrical contact designed to provide connection to a rotating part. 